\title{
Have "new" methods in medical education reached German-speaking Central Europe: a survey
}

Martin Fandler ${ }^{1 \dagger}$, Marion Habersack ${ }^{2^{*}}$ and Hans P Dimai ${ }^{3}$

\begin{abstract}
Background: Simulation-based-training (SBT) in the education of health professionals is discussed as an effective alternative for knowledge and skills enhancement as well as for the establishment of a secure learning environment, for learners and patients. In the Anglo-American region, SBT and simulation and training centers (STC) are numbered as standard for medical training. In German-speaking Central Europe, priority is still given to the establishment of SBT and STC. The purpose of this study was (i) to survey the status quo relating to the existence and facilities of simulation and training centers at medical universities in German-speaking Central Europe and (ii) the evaluation of training methods, especially in the area of emergency medicine skills.
\end{abstract}

Methods: All public and private medical universities or medical faculties in Germany (36), Austria (4) and German-speaking Switzerland (3) were interviewed. In the survey, information regarding the existence and facilities of STCs and information with regards to the use of SBT in the area of emergency medicine was requested. The questions were partly posed in a closed-ended-, in an open-ended- and in a multiple choice format (with the possibility of selecting more than one answer).

Results: Of a total of 43 contacted medical universities/medical faculties, 40 ultimately participated in the survey. As decisive for the establishment of a STC the potential to improve the clinical-practical training and the demand by students were listed. Obligatory training in a STC during the first and sixth academic year was confirmed only by 12 institutions, before the first invasive procedure on patients by 17 institutions. 13 institutions confirmed the use of the STC for the further training of physicians and care-staff. Training for the acute care and emergency medicine skills in the field of pediatrics, for the most part, occurs decentralized.

Conclusions: New methods in medical training have reached German-speaking Central Europe, but the simulation and training centers vary in size, equipment or regarding their integration into the obligatory curriculum as much as the number and variety of the offering to be trained voluntarily or on an obligatory basis.

Keywords: Medical education, Emergency medicine, Simulation-based-training, Simulation and training center

\section{Background}

Simulation-based-training (SBT) in the education and advanced training of health professionals is discussed internationally as an effective alternative for knowledge enhancement, improvement of "behavioral learning outcomes" as well as for technical and team skills $[1,2]$. Based on theories and concepts of adult education or organizational psychology SBT is merchandized as an alternative - superior to the traditional learning and

\footnotetext{
* Correspondence: marion.habersack@medunigraz.at

'Equal contributors

${ }^{2}$ Office of the Vice Rector for Teaching \& Studies, Medical University of Graz, Auenbruggerplatz 2, 8036 Graz, Austria

Full list of author information is available at the end of the article
}

teaching scenarios - for the establishment of a secure learning environment, for learners and patients [3-5]. In this context many medical specialty fields use SBT (partially in simulation and training centers specifically built for this) in order to guarantee or optimize the quality of the training and, in further consequence, the quality of patient care [6,7]. Minimization of the "July effect" [8], the limitation of the strategy, "Learning by Doing" [9], - regarded critically by the public as well as by patients - or simply the reaction to resource scarcity (minimizing study time or training time, financial and/or staff resources) are listed, among other things, as additional reasons for the establishment of SBT or 
STCs [10]. The specific requirements for institutions and learners in the context of simulation-based medical education are multifaceted and complex. In that manner, referring to the conception and establishment of SBT or STCs simulation and training centers, not only the provision of learning facilities in general and of clinical equipment, models and manikins in particular, but also the integration of SBT into the curricula or the adoption of innovative teaching and learning methods are to be ensured [11-13]. The consistent application of reliable and valid instruments for the evaluation of simulation learning outcomes and the hesitant application of summative as well as formative assessments is an additional challenge discussed in the literature $[5,14,15]$. Within the framework of SBT, cognitive skills as well as non-cognitive skills can be imparted. Correspondingly, different assessment instruments ensue for different teaching and learning contents (e.g., performance-based clinical skills, critical thinking/problem-solving skills and/or abilities, behaviorand team interaction). Despite these requirements and challenges, especially in the Anglo-American region, SBT and STCs are numbered as standard for medical training and the optimization of framework requirements, new methodologies and competencies to be taught are demanded. In contrast, in German-speaking Central Europe, as shown in the study by Segarra et al. (2008), priority is still given to the establishment of SBT and STCs [16].

The objective of this study was

a) to survey the status quo relating to the existence and facilities of simulation and training centers (STC) at medical universities/faculties in Germany, Austria and Switzerland; and, presupposed the existence of a STC was affirmed,

b) the evaluation of training methods, especially in the area of emergency medicine skills (general and pediatric).

\section{Methods}

In the period from February 2011 to July 2011, all public and private medical universities or medical faculties (respectively, the university board of these institutions) in German-speaking Central Europe were asked to participate in a survey about the topic of simulation and training centers (STC). The dynamically fillable survey was sent via e-mail to the university board. The participating universities/faculties were assured of the anonymization of all data.

The focus on medical universities/medical faculties in German-speaking Central Europe - at the time of data collection, this included 36 universities/faculties in Germany, four in Austria and three in German-speaking Switzerland - was based on two considerations: a) avoidance of language barriers and

b) similarity of courses of study in relation to duration and content. In this context, medical college in Germany and in Austria is designed as a 6-year undergraduate program (after high school). After the successful completion of this course of studies/ examinations, the degree of Medical Doctor (MD) is awarded in Austria, and students become licensed physicians in Germany. In Switzerland, medical college is also designed with a total length of six years, but with the Bologna-compliant division into a 3-year bachelor program (after high school) and a 3 -year master program in clinical medicine. In Switzerland, the course of study is concluded with the Master of Medicine.

The survey focused on two subject areas:

(i) collection of general (administrative) data such as existence, size, financial resources, reasons for the establishment, infrastructure, and integration into the teaching (27 questions) as well as an additional question regarding the specialty fields represented in the simulation and training centers (one question). The wording of the questions in this subject area was in the style of a survey conducted in 2008 by Segarra, et al. (2008) [16],

(ii) collection of general emergency medical skills taught (22 questions) and skills taught particularly regarding pediatric emergencies (nine questions). Wording of questions in this subject area was developed especially for this precise survey and tested regarding their face-validity by an expert team. The expert team was composed of instructors of the institution, experts in the area emergency medicine/pediatrics, the scientific director of the local STC, and upper-semester students.

The questions were posed either in a closed-ended- or open-ended or multiple-choice format (with the possibility of selecting more than one answer).

\section{Ethics}

The work described in this paper was primarily an "administrative data" evaluation and therefore was exempt from requiring permission from the Ethikkommission der Medizinischen Universität Graz [17].

\section{Results}

Of a total of 43 contacted medical universities or medical faculties, 40 ultimately participated in the survey. This corresponds to a return rate of $93 \%$. 


\section{General data}

\section{Establishment of STCs/year}

36 institutions (of a total of 40 medical universities/medical faculties participating in the survey) indicated they had a simulation and training center at their disposal. Two institutions reported the planned establishment of a STC; one institution indicated the existence of a decentralized STC. Only one institution did not confirm the existence or planning of a STC.

35 institutions answered the questions regarding an expansion of STCs. Twenty-three of these 35 institutions confirmed the planned expansion of the STC in the next five years (e.g., greater number of phantoms, greater number of stations) and 20 medical universities/faculties indicated they want to increasingly incorporate STC s into the obligatory classes (Figure 1).

\section{Reasons for/against the establishment and the expansion of STCs}

Reasons that were listed as essential for the establishment of STCs were indicated by 36 medical universities/faculties (multiple responses were possible). Of these 36 institutions, 29 institutions mentioned the potential to improve the clinical-practical training, and respectively 17 centers the potential to minimize deficits in the clinical-practical training as decisive for the establishment of a STC. The demand by students was listed by 22 universities/faculties as decisive for the establishment of a STC. Eleven institutions indicated, with the establishment of a STC they were reacting to trends in medicine didactics.

32 of 40 institutions gave information regarding the reasons for the further expansion of a simulation and training center (multiple responses were possible). As relevant for the expansion of an existing STC, 18 of 32 institutions answering this question listed the need by students. The explicit demand by students for an expansion of the STC was listed by twelve institutions. 25 of 32 institutions mentioned the potential for improving the clinical-practical training as essential reason for the expansion of an existing STC.

The answers to this set of questions are depicted in Table 1 in condensed form.

As reasons against the establishment of a STC not depicted in the table) lacking financial resources (eleven of 19 responding institutions) and non-existing facilities (14 of 19 responding institutions) were listed. Lacking financial resources were additionally listed as main reason against the expansion of an existing STC (twelve of 16 responding institutions).

\section{Qualification of STC administrators}

The question which qualification the administrators of the simulation and training centers possess was answered by 37 institutions. Twelve medical universities/medical faculties confirm the administration of the STC by physicians with further training of a Master of Medical Education (MME) or equivalent education; 17 institutions are led by physicians without special academic training in medical didactics. 31 centers (36 responses) use physicians and students as teachers. Only five centers employed, for example, psychologists or certified care givers as teaching staff.

\section{Financing of STCS}

Regarding the financing of the initial equipment/the construction of a STC and the financing of the running expenses of a STC (multiple responses were possible), a majority of the institutions indicated financing via the college budget (initial equipment: 30/running expenses: 29). Tuition fees were listed by nine institutions as financing source for the initial equipment and by eight institutions for covering running expenses. Only seven

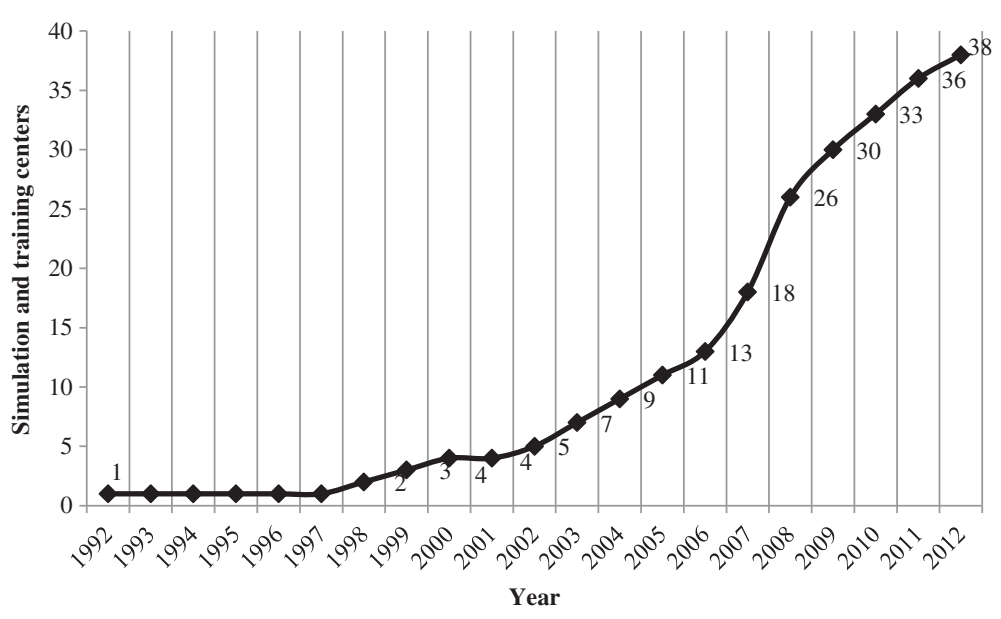

Figure 1 Establishment of STCs/year. 
Table 1 Reasons for the establishment and the expansion of STCs

\begin{tabular}{lllll}
\hline Reasons for & \multicolumn{2}{l}{$\begin{array}{l}\text { Establishment } \\
\text { (n= 36) }\end{array}$} & \multicolumn{2}{l}{$\begin{array}{l}\text { Expansion } \\
\text { (n= 32) }\end{array}$} \\
\hline Potential to improve clinical training & 29 & $80.56 \%$ & 26 & $81.25 \%$ \\
Student demand & 22 & $61.11 \%$ & 12 & $37.50 \%$ \\
Teacher demand & 9 & $25.00 \%$ & 10 & $31.25 \%$ \\
Department leadership demand & 11 & $30.56 \%$ & 6 & $18.75 \%$ \\
Others & 4 & $11.11 \%$ & 4 & $12.50 \%$ \\
Planned external cooperation & 3 & $8.33 \%$ & & \\
Combined individual projects & 9 & $25.00 \%$ & & \\
Existing deficits in clinical training & 17 & $47.22 \%$ & & \\
Current facilities not adequate & & & & \\
Necessity for student training & & & $61.25 \%$ & $56.25 \%$ \\
Necessity for mandatory training & & & $18.75 \%$ & $31.25 \%$ \\
Additional budget (from university) & & & 5 & $15.63 \%$ \\
Additional budget (e.g. sponsoring) & & &
\end{tabular}

institutions use/used private means for financing the construction and financing the running expenses of a STC (Table 2).

\section{Obligatory training in STCS}

The question, whether students are obligated to attend simulation and training centers during the various academic years, was answered by 31 centers. 22 institutions confirmed the obligatory attendance during the third academic year and 21 institutions each during the fourth and fifth academic year. Only at twelve institutions training in STCs is obligatory for students during the first academic year and sixth academic year. Obligatory training in a STC before the first invasive procedure on patients was confirmed by 17 institutions.

Of 36 responding institutions, only 13 institutions confirmed the use of the STC for the further training of physicians and care-staff. The question, whether didactic research is being conducted at the STCs, was answered positively by 20 institutions (37 responses). Nine centers confirmed that future research activities were being planned, and eight centers indicated they neither conducted nor planned didactic research (Table 3 ).

Table 2 Financing of the initial equipment and of the running expenses of STCs

\begin{tabular}{lrrrr}
\hline & $\begin{array}{c}\text { Initial equipment } \\
(\mathbf{n}=\mathbf{3 6})\end{array}$ & $\begin{array}{c}\text { Running expenses } \\
(\mathbf{n}=\mathbf{3 4})\end{array}$ \\
\hline College budget & 30 & $83.33 \%$ & 29 & $85.29 \%$ \\
Private sources & 7 & $19.44 \%$ & 7 & $20.59 \%$ \\
Others & 11 & $30.56 \%$ & 10 & $29.41 \%$ \\
Tuition fees (included in "Others") & 9 & $25.00 \%$ & 8 & $23.53 \%$ \\
Cooperation/sponsorship & 5 & $13.89 \%$ & 2 & $5.88 \%$ \\
\hline
\end{tabular}

Table 3 Obligatory training in STCs

\begin{tabular}{llc}
\hline Year & \multicolumn{2}{c}{ Obligatory training $(\mathbf{n}=\mathbf{3 1})$} \\
\hline 1 & 12 & $38.71 \%$ \\
2 & 10 & $32.26 \%$ \\
3 & 22 & $70.97 \%$ \\
4 & 21 & $67.74 \%$ \\
5 & 21 & $67.74 \%$ \\
6 & 12 & $38.71 \%$ \\
\hline
\end{tabular}

\section{Distribution of specialties taught in STCS}

As seen from Table 4, a wide variety of clinical subjects/ specialty fields are taught in the STCs. At 32 centers (38 responses, multiple answers were possible) abilities/skills in internal medicine, at 31 centers abilities/skills in surgery, and at 29 centers abilities/skills in emergency medicine are taught. The clinical subjects/specialty fields: gynecology, orthopedics, trauma and orthopedic surgery and urology are offered at 25 simulation and training centers. Medical communication is taught in 24 centers. Only two centers offer topics around medical ethics. Individual centers indicated additional subject areas such as medical English, forensic medicine, psychosomatic medicine, geriatric medicine or micro surgery as classes (not depicted in the table).

\section{Emergency medical abilities}

The second range of topics in the questionnaire focused on emergency medical abilities and skills that are taught at the STCs. 22 skills in the general and 9 skills in the area of pediatric acute care and emergency medicine were

\section{Table 4 Distribution of specialties}

\begin{tabular}{llr}
\hline & \multicolumn{2}{c}{ Specialties $(\mathbf{n}=\mathbf{3 8})$} \\
\hline Internal medicine & 32 & $84.21 \%$ \\
Surgery & 31 & $81.58 \%$ \\
Emergency medicine & 29 & $76.32 \%$ \\
Anesthesiology/critical care & 26 & $68.42 \%$ \\
Obstetrics/gynaecology & 25 & $65.79 \%$ \\
Trauma-/orthopaedic surgery & 25 & $65.79 \%$ \\
Urology & 25 & $65.79 \%$ \\
General-/family medicine & 24 & $63.16 \%$ \\
Medical communication & 24 & $63.16 \%$ \\
Neurology & 22 & $57.89 \%$ \\
Otolaryngology & 19 & $50.00 \%$ \\
Pediatrics & 19 & $50.00 \%$ \\
Radiology & 14 & $36.84 \%$ \\
Ophthalmology & 13 & $34.21 \%$ \\
Pneumology & 12 & $31.58 \%$ \\
Psychiatry/psychology & 8 & $21.05 \%$ \\
Medical ethics & 2 & $5.26 \%$ \\
\hline
\end{tabular}


enquired about. Medical universities/medical faculties participating in this collection of data could choose four answers (multiple responses were possible): a) skill is taught in the STC in the frame work of obligatory subjects, b) skill can voluntarily be trained by students in the STC, c) the establishment of appropriate training possibilities is being planned, and d) the skill is taught outside the STC.

\section{General emergency medicine skills}

In the area of general emergency medicine skills, 23 institutions indicated they offer, for example, training for advanced life support (according to the European Resuscitation Council, ERC) and the use of automatic defibrillators in the STC in the frame work of the obligatory subjects. Voluntary training for a simple cutaneous suture or the placing of a central venous access was listed by 17 institutions. The planning of appropriate training possibilities with regards to the application of dressings (including compression bandage) and the interpretation of radiological emergency findings (fracture, intra-cranial bleeding, etc.) was affirmed by six institutions. According to the information given by the centers, training for the internal (16 institutions), the neurological (17 institutions) and the surgical emergency check (15 institutions) is performed most frequently in a decentralized manner, that is, at the respective departments themselves. 21 universities/faculties indicate that the placement of a peripheral venous access, stabilization of the cervical spine and the interpretation of an emergency ECG's (including STEMI/NSTEMI) are taught in the STCs within the framework of the obligatory subjects. Voluntary training is offered in the STCs for placing an arterial access (15 centers), bag-valve ventilation (twelve centers) or advanced trauma care (ATLS or ETC or comparable alternatives) (eleven centers) (Table 5).

\section{Acute care and emergency medicine skills: pediatrics}

Training for the acute care and emergency medicine skills in the field of pediatrics, for the most part, occurs decentralized, that is, at the respective clinics. Students can train pediatric bag-valve ventilation, intubation of children with a laryngoscope and alternative airway devices (larynx tube, etc.) in twelve STCs on a voluntary basis. In the frame work of obligatory classes, for example, pediatric basic life support (ERC) is taught in STCs in twelve institutions, and the placement of intraosseous access or the examination of a pediatric emergency patient in seven institutions in STCs (Table 6).

Table 5 General emergency medicine skills

\begin{tabular}{|c|c|c|c|c|c|c|c|c|c|}
\hline \multirow[b]{2}{*}{ Focused examination (internal medicine) } & \multirow{2}{*}{$\begin{array}{r}\mathbf{n} \\
32\end{array}$} & \multicolumn{2}{|c|}{ Mandatory } & \multicolumn{2}{|c|}{ Voluntary } & \multicolumn{2}{|c|}{ Planned } & \multicolumn{2}{|c|}{ Decentralized } \\
\hline & & 13 & $40.6 \%$ & 10 & $31.3 \%$ & 4 & $12.5 \%$ & 16 & $50.0 \%$ \\
\hline Focused examination (neurology) & 29 & 9 & $31.0 \%$ & 6 & $20.7 \%$ & 4 & $13.8 \%$ & 17 & $58.6 \%$ \\
\hline Focused examination (trauma) & 31 & 13 & $41.9 \%$ & 8 & $25.8 \%$ & 3 & $9.7 \%$ & 15 & $48.4 \%$ \\
\hline IV access, peripheral & 37 & 21 & $56.8 \%$ & 15 & $40.5 \%$ & 4 & $10.8 \%$ & 7 & $18.9 \%$ \\
\hline IV access, central & 29 & 8 & $27.6 \%$ & 17 & $58.6 \%$ & 4 & $13.8 \%$ & 7 & $24.1 \%$ \\
\hline Arterial line & 31 & 7 & $22.6 \%$ & 15 & $48.4 \%$ & 5 & $16.1 \%$ & 8 & $25.8 \%$ \\
\hline Bag-valve ventilation & 35 & 24 & $68.6 \%$ & 12 & $34.3 \%$ & 1 & $2.9 \%$ & 15 & $42.9 \%$ \\
\hline Orotracheal intubation & 35 & 25 & $71.4 \%$ & 9 & $25.7 \%$ & 2 & $5.7 \%$ & 14 & $40.0 \%$ \\
\hline Alternative airway devices (LT, LMA etc.) & 34 & 22 & $64.7 \%$ & 7 & $20.6 \%$ & 3 & $8.8 \%$ & 14 & $41.2 \%$ \\
\hline Wound dressing & 33 & 16 & $48.5 \%$ & 12 & $36.4 \%$ & 6 & $18.2 \%$ & 10 & $30.3 \%$ \\
\hline Simple cutaneous sutures & 37 & 21 & $56.8 \%$ & 17 & $45.9 \%$ & 5 & $13.5 \%$ & 14 & $37.8 \%$ \\
\hline Splinting of extremities & 31 & 16 & $51.6 \%$ & 7 & $22.6 \%$ & 2 & $6.5 \%$ & 14 & $45.2 \%$ \\
\hline C-spine stabilization & 33 & 21 & $63.6 \%$ & 8 & $24.2 \%$ & 1 & $3.0 \%$ & 11 & $33.3 \%$ \\
\hline Extrication of injured patient & 31 & 19 & $61.3 \%$ & 6 & $19.4 \%$ & 2 & $6.5 \%$ & 10 & $32.3 \%$ \\
\hline AED usage & 34 & 23 & $67.6 \%$ & 6 & $17.6 \%$ & 2 & $5.9 \%$ & 12 & $35.3 \%$ \\
\hline Defibrillator- (manual, semi-manual) usage & 33 & 25 & $75.8 \%$ & 5 & $15.2 \%$ & 2 & $6.1 \%$ & 11 & $33.3 \%$ \\
\hline Emergency ECG interpretation & 34 & 21 & $61.8 \%$ & 10 & $29.4 \%$ & 2 & $5.9 \%$ & 11 & $32.4 \%$ \\
\hline Emergency radiology interpretation & 30 & 6 & $20.0 \%$ & 8 & $26.7 \%$ & 6 & $20.0 \%$ & 18 & $60.0 \%$ \\
\hline Trauma emergency sonography (FAST etc.) & 24 & 5 & $20.8 \%$ & 6 & $25.0 \%$ & 3 & $12.5 \%$ & 13 & $54.2 \%$ \\
\hline Advanced trauma care (ATLS, ETC etc.) & 27 & 8 & $29.6 \%$ & 11 & $40.7 \%$ & 4 & $14.8 \%$ & 12 & $44.4 \%$ \\
\hline Basic life support (ERC/AHA) & 35 & 26 & $74.3 \%$ & 6 & $17.1 \%$ & 2 & $5.7 \%$ & 13 & $37.1 \%$ \\
\hline Advanced life support (ERC/AHA) & 35 & 23 & $65.7 \%$ & 6 & $17.1 \%$ & 3 & $8.6 \%$ & 13 & $37.1 \%$ \\
\hline
\end{tabular}


Table 6 Acute care and emergency medicine skills: pediatrics

\begin{tabular}{|c|c|c|c|c|c|c|c|c|c|}
\hline \multirow[b]{2}{*}{ Pediatric basic life support } & \multirow{2}{*}{$\frac{\mathbf{n}}{30}$} & \multicolumn{2}{|c|}{ Mandatory } & \multicolumn{2}{|c|}{ Voluntary } & \multicolumn{2}{|c|}{ Planned } & \multicolumn{2}{|c|}{ Decentralized } \\
\hline & & 12 & $40.0 \%$ & 9 & $30.0 \%$ & 3 & $10.0 \%$ & 12 & $40.0 \%$ \\
\hline Pediatric advanced life support & 26 & 8 & $30.8 \%$ & 9 & $34.6 \%$ & 3 & $11.5 \%$ & 11 & $42.3 \%$ \\
\hline Focused examination (pediatrics) & 24 & 7 & $29.2 \%$ & 4 & $16.7 \%$ & 5 & $20.8 \%$ & 17 & $70.8 \%$ \\
\hline IV access, peripheral & 24 & 3 & $12.5 \%$ & 8 & $33.3 \%$ & 2 & $8.3 \%$ & 14 & $58.3 \%$ \\
\hline $\begin{array}{l}\text { Alternative application of medication } \\
\text { (rectal, buccal, nasal, intramuscular) }\end{array}$ & 22 & 3 & $13.6 \%$ & 6 & $27.3 \%$ & 1 & $4.5 \%$ & 15 & $68.2 \%$ \\
\hline Intraosseous access & 23 & 7 & $30.4 \%$ & 8 & $34.8 \%$ & 3 & $13.0 \%$ & 10 & $43.5 \%$ \\
\hline Bag-valve ventilation & 28 & 9 & $32.1 \%$ & 12 & $42.9 \%$ & 2 & $7.1 \%$ & 15 & $53.6 \%$ \\
\hline Orotracheal intubation & 25 & 7 & $28.0 \%$ & 12 & $48.0 \%$ & 1 & $4.0 \%$ & 12 & $48.0 \%$ \\
\hline Alternative airway devices (LT, LMA etc.) & 28 & 8 & $28.6 \%$ & 12 & $42.9 \%$ & 3 & $10.7 \%$ & 13 & $46.4 \%$ \\
\hline
\end{tabular}

\section{Discussion}

The objective of the current study was to survey the status quo of simulation and training centers at medical universities/medical faculties in Germany, Austria and German-speaking Switzerland, and to gain an overview of offered emergency medicine training methods/activities. Of 43 contacted medical universities/medical faculties, 40 institutions ultimately participated in the data collection. The results of the investigation document firstly the rising number of STCs as well as the definite commitment to the expansion of STCs in German-speaking Central Europe. Whereas in the year 2007 simulation and training centers existed at 13 medical universities/medical faculties, already 38 medical universities confirmed the establishment of a STC in 2012. This "trend" was already diagnosed by the results of Segarra et al. (2008), and - at least for Germany - attributed to the reform of the medical licensure law in the year 2002 and to the levy of tuition fees in the year 2006 [16]. The establishment of STCs or simulation-based education before this time can, in an international comparison, be interpreted as unassertive [18]. As essential reasons for the construction or the expansion of a simulation and training center the polled medical universities / medical faculties listed the potential to improve clinical-practical training, deficits in the training, didactic considerations, and the explicit demand by students. This corresponds to the areas mentioned in numerous publications in which simulationbased training is mentioned as a possibility for change, improvement or development. In this context, Bradley et al. (2003) list the areas: fundamental reforms in medical education, the "adoption" of the concept of clinical governance, deficits in medical training and the potential to answer to altered requirements with adequate course offerings $[11,19,20]$. The safety and optimization of patient care are listed as further areas that argue for simulationbased medical education [2,20,21].

The polled centers mentioned the lack of financial resources as essential reason speaking against the establishment or expansion of a STC. The literature, as well, refers to the not insubstantial costs of a simulation and training center and considers these, among other things, also responsible for the hesitant implementation of the same $[5,18,22,23]$. Those points of time in the framework of medical training at which obligatory training in a STC is stipulated are doubtlessly associated with patient safety. The results from the data collection show that this "obligation", on one hand, exists before clinical training and, on the other hand, in the fourth or fifth academic year. This corresponds to the implementation of (high-fidelity) simulator exercises, common internationally, in the pre-clinical as well as in the clinical part of the curriculum [24]. McGaghie et al. - in their qualitative synthesis published in the year 2010 furthermore refer to the importance of and also the difficulties with the integration of simulation-based medical education in curricula [15]. Currently - as the results of the present data collection show - the STCs are predominantly used for students. This does not correspond to the results of numerous studies that point out the definitely positive effect of simulation-based education on the clinical skills of post-graduates [25,26].

As Table 4 in the results section shows, a variety of subjects is taught in the simulation and training centers in Germany, Austria and German-speaking Switzerland. Internal medicine, surgery as well as emergency medicine, as cross-sectional area, are offered most frequently.

The results from the second range of topics in the questionnaire - where general emergency medicine skills and emergency medicine skills in the area of pediatrics were the focus- show a great variability in the "offering". Classic emergency medicine skills are frequently offered in the framework of obligatory subjects in the STCs; however, the number of skills offered to be trained voluntarily is low. This seems all the more surprising as definite indications already exist for the fact that simulation-based medical education could - among other things, in the area of emergency medicine -minimize potential complications, 
increase trainee safety, or simply could, as Singer et al. (2013), among others, document, lead to better results for residents (with simulation-based training) in comparison to residents without simulation-based training [27].

Emergency medicine skills in the area of pediatrics are rarely offered in the polled STCs in the context of obligatory classes, but would- though not prevalent -in no case be a negligible tool [28]. Though, as Kessler et al. (2013) indicate, there are few studies on whether SBT has an improved clinical impact on pediatric patients, among other things, the exceedingly positive effects of SBT in the area of echocardiography in congenital heart diseases with children is pointed out [29]. In any case, one has to assume that, even in the context of pediatric emergency medicine, parents and/or relatives as well as residents would welcome comprehensive SBT [26].

In summary, it can be noted that the STCs in Germanspeaking Central Europe vary strongly in their facilities, their resources, in their utilization, in their offerings, and in the qualification of the teachers/instructors. In the words of Beckers et al. (2009), "The innovative options of simulation technology or state-of-the-art assessment methods are not consistently utilized" [13]. Admittedly, recommendations exist developed by and for various medical/care-giving specialty fields.

For Germany, the efforts of the German Medical Faculty Association and the German Medical Association (GMA) to create a Germany-wide competency-based catalogue of learning objectives for undergraduate medical education, will not only define the levels needed to be taught to students but also further the importance of SBT and associated STCs [30]. This might be a way to promote the same basic level of emergency medical education and SBT at all German universities. Also, this catalogue could be a model for Austria, where no nation-wide competency-based catalogue currently exists.

However, currently there are no minimal standards for SBT und STCs applicable to all of Europe. The agreement on minimal standards applying to all of Europe (the results of the EU project Simbase, among others, would have to be valued as a possible starting point for this), in turn have to be interpreted as potential starting point for an Europe-wide accreditation of STCs [31]. Minimal standards - as they are planned, e.g., internationally by the Society for Simulation and Health Care for the accreditation of STCs - would be, not least, essential for a barrier-free mobility for students and work in Europe [32]. In this context, the Europe-wide ascertainment of the status quo of SBT and STCs would have to be assessed as first step towards formulating minimal standards.

\section{Limitations}

Though the present survey represents the status quo regarding SBT and STC at medical faculties in German- speaking Central Europe almost completely (response rate 93\%), the inclusion of all European countries in a survey concerning this matter is a next necessary step.

\section{Conclusions}

In summary, one gets the impression that new methods in medical training have reached German-speaking Central Europe, but that the simulation and training centers vary greatly in size, equipment or regarding their integration into the obligatory curriculum as much as the number and variety of the offering to be trained voluntarily or on an obligatory basis. Still, questions about financial feasibility and about the "necessity" (teachers versus students) remain in the foreground and further complicate the - already hesitant, in international comparison - development or the realization of a systematic assessment of the outcomes. The limitation of the training offering to students (i.e., graduated physicians or other health professionals are rarely addressed) and only minimal collaboration with other institutions in health care, on no account, argue for a possible termination of "financial crises".

However, the number of existing simulation and training centers in German-speaking Central Europe can be seen as indication that the importance of SBT for the quality of medical training and patient care was recognized.

\section{Abbreviations}

AED: Automated external defibrillator; AHA: American heart association; ALS: Advanced life support; ATLS: Advanced trauma life support; ECG: Electrocardiogram; ENT: Ear, nose, throat (otolaryngology); ERC: European Resuscitation Council; ETC: European trauma course; FAST: Focused assessment with sonography in trauma; IM: Intramuscular; IV: Intravenous; LMA: Laryngeal mask airway; LT: Laryngeal tube; MME: Master of medical education; NSTEMI: Non-ST-elevation myocardial infarction; OB/GYN: Obstetrics/gynaecology; SBT: Simulation-based-training; STC: Simulation and training center; STEMI: ST-elevation myocardial infarction.

\section{Competing interests}

The authors declare that they have no competing interests.

\section{Authors' contributions}

MF participated in the design of the study, performed the data collection and analysis and revised the manuscript critically. MH contributed in the interpretation of data and drafted the manuscript. HPD participated in the design of the study and helped to draft the manuscript. All authors read and approved the final manuscript.

\section{Author details}

'Department of Emergency and Critical Care Medicine, Nuremberg Hospital, Prof-Ernst-Nathan-Str., 1, 90419 Nuremberg, Germany. ${ }^{2}$ Office of the Vice Rector for Teaching \& Studies, Medical University of Graz, Auenbruggerplatz 2, $8036 \mathrm{Graz}$, Austria. ${ }^{3}$ Department of Internal Medicine, Division of Endocrinology \& Metabolism, Medical University of Graz, Auenbruggerplatz 2, 8036 Graz, Austria.

Received: 18 June 2014 Accepted: 12 August 2014

Published: 16 August 2014 


\section{References}

1. Meurling L, Hedman L, Felländer-Tsai L, Wallin C-J: Leaders' and followers' individual experiences during the early phase of simulation-based team training: an exploratory study. BMJ Qual Saf 2013, 22(6):459-467.

2. Salas E, Paige JT, Rosen MA: Creating new realities in healthcare: the status of simulation-based training as a patient safety improvement strategy. BMJ Qual Saf 2013, 22(6):449-452.

3. Akaike M, Fukutomi M, Nagamune M, Fujimoto A, Tsuji A, Ishida K, Iwata T: Simulation-based medical education in clinical skills laboratory. J Med Invest 2012, 59(1-2):28-35.

4. King A, Holder MG, Ahmed RA: Errors as allies: error management training in health professions education. BMJ Qual Saf 2013, 22(6):516-519.

5. Kardong-Edgren S, Adamson KA, Fitzgerald C: A review of currently published evaluation instruments for human patient simulation. Clin Simul Nurs 2010, 6(1):e25-e35.

6. Barsuk JH, Cohen ER, Feinglass J, McGaghie WC, Wayne DB: Unexpected Collateral Effects of Simulation-Based Medical Education. Acad Med 2011, 86(12):1513-1517. 1510.1097/ACM.1510b1013e318234c318493.

7. Bray BS, Schwartz CR, Odegard PS, Hammer DP, Seybert AL: Assessment of Human Patient Simulation-Based Learning. Am J Pharm Educ 2011, 75(10):208.

8. Cohen ER, Barsuk JH, Moazed F, Caprio T, Didwania A, McGaghie WC, Wayne DB: Making July Safer: Simulation-Based Mastery Learning During Intern Boot Camp. Acad Med 2013, 88(2):233-239. 210.1097/ ACM.1090b1013e31827bfc31820a.

9. Eckstein H-H, Schmidli J, Schumacher H, Gürke L, Klemm K, Duschek N Meile T, Assadian A: Rationale, scope, and 20-year experience of vascular surgical training with lifelike pulsatile flow models. J Vasc Surg 2013, 57(5):1422-1428

10. Cook DA, Brydges R, Zendejas B, Hamstra SJ, Hatala R: Technology-Enhanced Simulation to Assess Health Professionals: A Systematic Review of Validity Evidence, Research Methods, and Reporting Quality. Acad Med 2013 88(6):872-883. 810.1097/ACM.1090b1013e31828ffdcf.

11. Bradley P, Postlethwaite K: Setting up a clinical skills learning facility. Med Educ 2003, 37(Suppl 1):6-13.

12. Gordon J, Hazlett C, Ten Cate O, Mann K, Kilminster S, Prince K, O'Driscoll E, Snell L, Newble D: Strategic planning in medical education: enhancing the learning environment for students in clinical settings. Med Educ 2000, 34(10):841-850.

13. Beckers S, Timmermann A, Müller M, Angstwurm M, Walcher F: Undergraduate medical education in emergency medical care: A nationwide survey at German medical schools. BMC Emerg Med 2009, 9(1):1-9.

14. Huang GC, Sacks H, DeVita M, Reynolds R, Gammon W, Saleh M, Gliva-McConvey G, Owens T, Anderson J, Stillsmoking K: Characteristics of Simulation Activities at North American Medical Schools and Teaching Hospitals: An AAMC-SSHASPE-AACN Collaboration. Simul Healthc 2012, 7(6):329-333.

15. McGaghie WC, Issenberg SB, Petrusa ER, Scalese RJ: A critical review of simulation-based medical education research: 2003-2009. Med Educ 2010, 44(1):50-63.

16. Segarra LM, Schwedler A, Weih M, Hahn EG, Schmidt A: Der Einsatz von medizinischen Trainingszentren für die Ausbildung zum Arzt in Deutschland, Österreich und der deutschsprachigen Schweiz.[Clinical Skills Labs in Medical Education in Germany, Austria and German Speaking Switzerland.]. GMS Z Med Ausbild 2008, 25(2):1-7.

17. Medical University Graz: Ethikkommission. [http://www.medunigraz.at/ ethikkommission/Graz/]

18. Rosen KR: The history of medical simulation. J Crit Care 2008, 23(2):157-166

19. Bradley P, Postlethwaite K: Simulation in clinical learning. Med Educ 2003, 37(Suppl 1):1-5

20. Wheeler DS, Geis G, Mack EH, LeMaster T, Patterson MD: High-reliability emergency response teams in the hospital: improving quality and safety using in situ simulation training. BMJ Qual Saf 2013, 22(6):507-514

21. Ross AJ, Anderson JE, Kodate N, Thomas L, Thompson K, Thomas B, Key S, Jensen $H$, Schiff $R$, Jaye P: Simulation training for improving the quality of care for older people: an independent evaluation of an innovative programme for inter-professional education. BMJ Qual Saf 2013, 22(6):495-505.

22. Vyas D, Bray BS, Wilson MN: Use of Simulation-based Teaching Methodologies in US Colleges and Schools of Pharmacy. Am J Pharm Educ 2013, 77(3):53.
23. Good ML: Patient simulation for training basic and advanced clinical skills. Med Educ 2003, 37(Suppl 1):14-21.

24. Sperling JD, Clark S, Kang Y: Teaching medical students a clinical approach to altered mental status: simulation enhances traditional curriculum. Medical Education Online 2013, 18:1-18.

25. Cook DA, Hatala R, Brydges R, Zendejas B, Hamstra SJ, Hatala R: Technology-enhanced simulation for health professions education: $A$ systematic review and meta-analysis. JAMA 2011, 306(9):978-988.

26. Kessler DO, Arteaga G, Ching K, Haubner L, Kamdar G, Krantz A, Lindower J, Miller M, Petrescu M, Pusic MV, Rocher J, Shah N, Strother C, Tilt L, Weinberg ER, Chang TP, Fein DM, Auerbach M: Interns' success with clinical procedures in infants after simulation training. Pediatrics 2013, 131(3):e811.

27. Singer BD, Corbridge TC, Schroedl CJ, Wilcox JE, Cohen ER, McGaghie WC, Wayne DB: First-Year Residents Outperform Third-Year Residents After Simulation-Based Education in Critical Care Medicine. Simul Healthc 2013, 8(2):67-71.

28. Cloutier RL, Walthall JDH, Mull CC, Nypaver MM, Baren JM: Best Educational Practices in Pediatric Emergency Medicine During Emergency Medicine Residency Training: Guiding Principles and Expert Recommendations. Acad Emerg Med 2010, 17:S104-S113.

29. Wagner R, Razek V, Gräfe F, Berlage T, Janoušek J, Daehnert I, Weidenbach M: Effectiveness of Simulator-Based Echocardiography Training of Noncardiologists in Congenital Heart Diseases. Echocardiography 2013, 30(6):693-698

30. Hahn E, Fischer M: Nationaler Kompetenzbasierter Lernzielkatalog Medizin (NKLM) für Deutschland: Zusammenarbeit der Gesellschaft für Medizinische Ausbildung (GMA) und des Medizinischen Fakultätentages (MFT). GMS Z Med Ausbild 2009, 26(3):2009-2026.

31. Simbase: Promotion of ICT enhanced Simulation Based Learning in Healthcare. [http://www.simbase.co/]

32. Society for Simulation in Healthcare: SSH. [http://ssih.org]

doi:10.1186/1472-6920-14-172

Cite this article as: Fandler et al:: Have "new" methods in medical education reached German-speaking Central Europe: a survey. BMC Medical Education 2014 14:172.

\section{Submit your next manuscript to BioMed Central and take full advantage of:}

- Convenient online submission

- Thorough peer review

- No space constraints or color figure charges

- Immediate publication on acceptance

- Inclusion in PubMed, CAS, Scopus and Google Scholar

- Research which is freely available for redistribution 